\title{
Neuro Cognitive Improvement During Pregnancy: An Auditory Event Related Potential (ERP) and Neuropsychological Study
}

\author{
Atiyah Ali ${ }^{1}$, Tahamina Begum ${ }^{1 *}$, Faruque Reza ${ }^{1}$, Wan Rosilawati Wan Rosli ${ }^{2}$ and Wan Nor Azlen \\ Wan Mohamad ${ }^{1}$ \\ ${ }^{1}$ Department of Neurosciences, School of Medical Sciences, Universiti Sains Malaysia, 16150 Kubang Kerian, Kota Bharu, Kelantan, Malaysia \\ ${ }^{2}$ Department of Obstetrics and Gynaecology, School of Medical Sciences, Universiti Sains Malaysia, Kubang Kerian 16150, Kota Bharu, Kelantan, \\ Malaysia
}

${ }^{*}$ Corresponding author: Tahamina Begum, Department of Neurosciences, School of Medical Sciences, Universiti Sains Malaysia, Kubang Kerian, Kota Bharu, Kelantan, Malaysia, Tel: Ext- (609) 767 6315, HP: +6-017-9678408; Fax: (609) 767 6315; E-mail: tahaminabegum70@hotmail.com

Rec Date: February 13, 2018; Acc Date: March 28, 2018, 2018; Pub Date: March 31, 2018

Citation: Ali A, Begum T, Reza F, Rosli WRW, Mohamad WNAW (2018) Neuro Cognitive Improvement during Pregnancy: An Auditory Event Related Potential (ERP) and Neuropsychological Study. J Neurol Neurosci Vol.9 No.2:254.

\section{Abstract}

Background: Although there is increasing research interest in auditory cognitive function among pregnant women, little is known about auditory cognitive function during the second (mid) and third trimesters of pregnancy. Therefore, we investigated auditory cognitive and behavioral functions during the mid- and third trimesters of pregnancy using event related potentials (ERPs) and neuropsychological tests, respectively.

Methods: ERPs were examined using a 128-sensor net, and the PAS, WCST, ZCT, RAVLTIM, RAVLTDR, RAVLTTS were administered as neuropsychological assessment tools. Thirty-nine participants were recruited as a control group ( $G 1, n=15$, non-pregnant), mid trimester ( $G 2, n=12$, 13-26 weeks), and third trimester (G3, $n=12,26-40$ weeks). The auditory oddball paradigm was used during the ERP examination. Subjects silently counted the number of occurrences of a target tone while ignoring the standard tone.

Results: The value of mean differences of two stimuli were measured in case of amplitudes of P50, N100 and P300 ERP components. The highest (significantly) amplitudes were found in three, three and two sites in P50, N100 and P300 ERP components, respectively. Pregnant group (G2 and G3 both) evoked the highest (significantly) amplitudes in three, one and two sites in P50, N100 and P300 components, respectively, comparing with the control group (G1). Within pregnant group, G3 possesses the highest (significantly) amplitudes at 2 sites (out of 3 ) in P50, 1 site (out of 3 ) in $\mathrm{N} 100$ and 1 site (out of 2 ) in P300 components. The highest amplitude of P300 was observed in G2 comparing with the G3. G2 subjects achieved the highest (significantly/nearly significantly) scores on the WCST, RAVLTIM; where G1 subjects had the highest score in ZCT among groups.
Conclusion: These findings indicate that pregnant women exhibit good auditory attention, memory and executive function. Pregnant women exhibited better auditory cognitive function in the second trimester compared with those in the third trimester of pregnancy.

Keywords: Pregnancy; Auditory cognition; WCST; PAS; ZCT; RAVLTs; P300; P50; N100

\section{Introduction}

Cognitive functioning is essential for the maintenance of social responsibilities, family, and work. Any deficit in cognitive function can have a negative impact on functioning in daily life. Several studies have investigated the cognitive function of pregnant women, often reporting a tendency for pregnant women to be forgetful, with impaired focus [1] and poor memory [2]. Cognitive changes during pregnancy are thought to be related to hormonal fluctuations $[3,4]$ and depression [5]. However, previous studies of cognitive abilities among pregnant women have often involved subjective measures, and cognitive findings may be affected by factors related to depression. Therefore, the current study integrated both objective and subjective tests using event related potentials (ERPs) and neuropsychological tests, respectively. In humans, pregnancy involves three trimesters. Each trimester is associated with fluctuations of sex hormones to support and maintain fetal development. The current study was performed to compare the auditory cognitive function of pregnant women using auditory oddball stimuli in the mid and third trimesters of pregnancy.

The recruitment of neural resources is important for assessing attention deficits among pregnant women. ERPs are an electrophysiological tool that can be used to investigate brain activity during cognitive processing and can play a valuable role in assessing attention by measuring the amplitudes and latencies of various ERP components. ERP measurement enables evaluation of electrophysiological signals from the brain that occur directly after the 
presentation of a stimulus event. ERP is a non-invasive technique that is safe to implement with patients as well as healthy subjects [6]. ERPs provide a convenient tool not only for attention study, but also for recognition memory, visual working memory and long-term memory [7]. In one study, visual cognitive function was investigated using different faces and shapes among third trimester pregnant women, revealing that pregnant women had poorer visual cognitive control and reduced P300 amplitude [8]. Another study reported that a pregnant group exhibited greater amplitudes and latencies of the P300 component compared with the control group [9].

A recent study combining ERPs and neuropsychological measures was conducted with mid trimester pregnant women, reporting mild auditory cognitive functional impairment among pregnant women, with no impairment of executive function and auditory memory [10]. However, to date, no previous studies have examined the cognitive function of pregnant women between mid and third trimester pregnancy using both ERPs and neuropsychological measures. Therefore, the current study sought to assess auditory cognitive function among mid and third trimester pregnant women using ERPs and neuropsychological tests. The current findings may help future studies elucidate the precise characteristics of neuronal network processing among pregnant women, aiding the development of therapeutic or rehabilitation approaches for improving auditory cognition among pregnant women.

\section{Methods}

\section{Subjects}

Thirty-nine subjects were recruited with control (G1) (mean age \pm SD $32.59 \pm 3.75, n=15$ ) and pregnant subjects. Pregnant subjects were divided into two subgroups based on the stage of pregnancy: second trimester (G2) $(27.19 \pm 2.92, \mathrm{n}=12)$ and third trimester (G3) $(27.89 \pm 4.57, n=12)$ groups. The second trimester, also known as the mid trimester, occurs from 13 to 26 weeks, and the third trimester occurs within 27 to 40 weeks of gestation [1]. Subjects in the first trimester of pregnancy were not included in the current study because of safety concerns. All participants in both groups were age and education matched, not under treatment or have any major diseases for example hypertension, diabetes, kidney diseases, obesity, drug addiction etc and all women have 1-3 child/ children. We included all participants in both groups within 20-40 years old as this are the childbearing age [11] education was more than STPM (Sijil Pelajaran Tinggi Malaysia: 13 education years) as low education reflects lower cognitive function (attention) [12,13], even major diseases and drug addiction also reflects on cognitive function [14-16]. There are cognitive function differences between single and married women. Therefore, we matched all participants in both groups as married with 1-3 children [17].

This study was approved by the Human Ethical Committee of Universiti Sains Malaysia (USM). Written informed consent was obtained from all participants prior to the experiment. Neuropsychological tests were conducted by an expert clinical neuropsychologist. ERPs were recorded in the Laboratory for MEG and ERP studies at Hospital Universiti Sains Malaysia (HUSM) using a 128-electrode sensor net.

\section{ERP procedure}

E-Prime v 2.0 software (Psychology Software Tools, Inc, Sharpsburg, Pennysylvania, USA) was used for presentation of stimuli, timing operations and data collection. Participants were seated in a dimly lit room with headphones placed on both ears, while wearing a 128-electrode sensor net. Subjects were instructed to silently count the target tones (60 dB sound pressure level (SPL) which were low frequency (20\%) with high pitch $(2000 \mathrm{~Hz}))$, presented binaurally, while ignoring standard tones (60 dB SPL, high frequency (80\%) and low pitched (1000 $\mathrm{Hz}$ )). Tone duration was $100 \mathrm{~ms}$ with a rise/fall time of $10 \mathrm{~ms}$. All data were recorded using Net-Station software (Electrical Geodesics, Inc., Eugene, OR, USA). The amplitudes of the P50, N100 and P300 ERP components were analyzed at 19 electrode locations in $10-20$ system.

\section{Neuropsychological tests}

Subjects were assessed using a range of neuropsychological tests. The Controlled Oral Word Association (COWA or PAS), Wisconsin card sorting test (WCST), Zazzo's cancellation test (ZCT) were performed to assess executive functions, the Rey Auditory Verbal and Learning Test (RAVLT) was used to assess auditory attention and memory assessment among groups.

\section{Data analysis}

A band-pass filter was set to $0.3-50 \mathrm{~Hz}$ with $0.5 \mathrm{~Hz}$ stimulus rate. The electrode impedance was kept below $50 \mathrm{~K} \Omega$. Data were segmented from $100 \mathrm{~ms}$ before stimulus presentation to 800 ms after stimuli. Artefacts such as eye blink, eye movements and movement artefacts, were removed using the artefact detection tool in Net-Station software. Baseline correction was performed $100 \mathrm{~ms}$ before stimuli. We examined the mean differences in amplitudes of the P50, $\mathrm{N} 100$ and P300 ERP components between responses to the target and standard stimuli, using 19 electrode channels (FP1, FP2, F3, F4, F7, F8, Fz, C3, C4, Cz, P3, P4, Pz, T3, T4, T5, T6, O1 and 02 ). To identify significant differences, the ERP and neuropsychological test data were analyzed using SPSS24 software with one-way ANOVA. The significance level was set to $p \leq 0.05$.

\section{Results}

Figure 1 shows the grand average waveforms of the P50, $\mathrm{N} 100$ and P300 ERP components, comparing the neural responses towards auditory stimulation between the control group (G1) (Figure 1a), the mid trimester pregnancy group (G2) (Figure 1b) and the third trimester pregnancy group (G3) (Figure 1c). Tables 1, 2 and $\mathbf{3}$ show the mean differences of amplitudes in the P50, N100 and P300 components, respectively, in responses to target and standard stimuli, between the three groups. 
(a) Control group

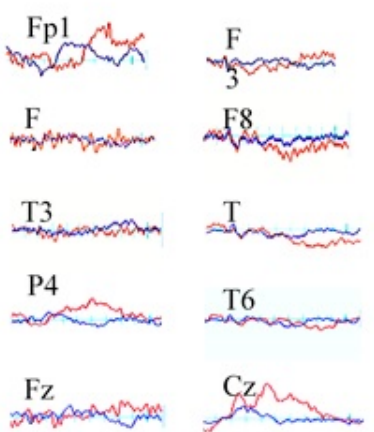

(b) Mid trimester pregnant group

F7

monorimen

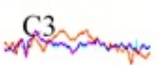

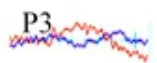

01 mancoupos

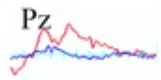

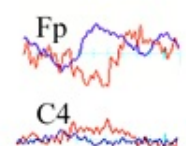

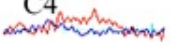

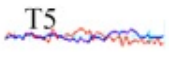

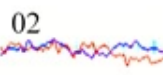

$7.96 \cos 10$
Fp1

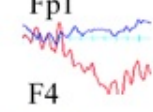

minniming

T3

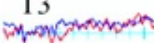

P4

mapranacicos

$\mathrm{Fz}$

strum

(c)Third trimester pregnant group (G3)

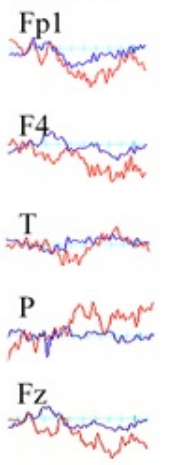

$\mathrm{F}$

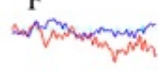

F8

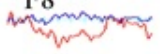

$\prod_{\text {Tam }}^{T}$

$\mathrm{T}$

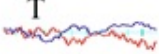

C
F7

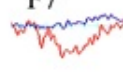

C3 3 mainams
P

F3

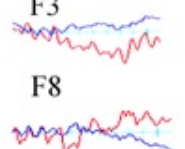

F7/mant

C3

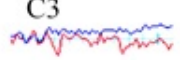

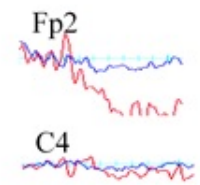

T4

arremopomancs

P3 manas

T5 mans

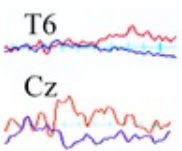

01 minn
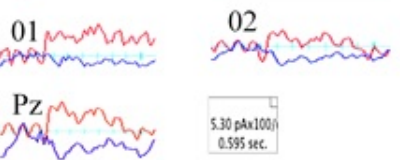

530 pentions

cosssect.

Figure 1 Grand average waveforms of the P50, N100 and P300 ERP components during target and standard stimuli within control (a) mid trimester pregnancy (b) third trimester pregnancy (c) groups at 19 electrodes sites $(n=15, n=12, n=12$ respectively). Standard stimuli (blue color) and target stimuli (red color).

\section{P50 ERP Component}

The amplitudes of the P50 ERP component were more clearly identified in the $\mathrm{G} 3$ group compared with the $\mathrm{G} 2$ and G1 groups. Significantly greater amplitudes of P50 ERP component were evoked across three channels ( $F 7, p=0.034$, and $\mathrm{C} 3, \mathrm{p}=0.034 ; \mathrm{G} 3>\mathrm{G} 1>\mathrm{G} 2)(\mathrm{T} 4, \mathrm{p}=0.031 ; \mathrm{G} 2>\mathrm{G} 3>\mathrm{G} 1)$. The group effects were $F(d f)=3.660(2,36), F(d f)=3.679(2,36)$ and $F(d f)=3.797(2,36)$, respectively (Table 1$)$.

Table 1 The amplitudes of P50 ERP component were shown across groups (control, 2nd trimester pregnancy and 3rd trimester pregnancy).

\begin{tabular}{|c|c|c|c|c|c|}
\hline \multirow[t]{2}{*}{ Sites } & \multirow{2}{*}{$\begin{array}{l}\text { Control (G1) (mean } \pm \\
\text { SD) }\end{array}$} & $\begin{array}{l}\text { 2nd trirmester Pregnancy(G2) } \\
\text { (mean } \pm \text { SD) }\end{array}$ & $\begin{array}{l}\text { 3rd trimester Pregnancy }(G 3) \\
\text { (mean } \pm \text { SD) }\end{array}$ & $F(d f)$ & \multirow[t]{2}{*}{$p$} \\
\hline & & \multicolumn{3}{|c|}{ P50 ERP Component Amplitudes (in mV) (mean \pm SD) } & \\
\hline $\mathrm{F} z$ & $1.27 \pm 0.61$ & $1.30 \pm 0.57$ & $1.70 \pm 1.11$ & $1.222(2,36)$ & 0.305 \\
\hline $\mathrm{Cz}$ & $0.70 \pm 0.53$ & $1.00 \pm 0.76$ & $1.02 \pm 0.53$ & $1.263(2,36)$ & 0.294 \\
\hline $\mathrm{Pz}$ & $1.07 \pm 0.80$ & $1.13 \pm 0.88$ & $1.52 \pm 0.85$ & $1.122(2,36)$ & 0.335 \\
\hline Fp1 & $1.60 \pm 1.06$ & $2.24 \pm 1.23$ & $1.80 \pm 0.92$ & $1.878(2,36)$ & 0.166 \\
\hline Fp2 & $1.63 \pm 1.67$ & $2.14 \pm 1.29$ & $2.55 \pm 0.85$ & $3.058(2,36)$ & 0.058 \\
\hline F3 & $1.16 \pm 0.48$ & $1.20 \pm 0.63$ & $1.53 \pm 0.68$ & $1.513(2,36)$ & 0.232 \\
\hline F4 & $0.93 \pm 0.47$ & $1.20 \pm 0.80$ & $1.22 \pm 0.77$ & $0.804(2,36)$ & 0.455 \\
\hline F7 & $1.11 \pm 0.65$ & $1.05 \pm 0.60$ & $1.71 \pm 0.85$ & $3.660(2,36)$ & 0.034 \\
\hline F8 & $0.98 \pm 0.70$ & $1.89 \pm 0.97$ & $1.23 \pm 0.73$ & $0.317(2,36)$ & 0.73 \\
\hline C3 & $0.86 \pm 0.32$ & $0.76 \pm 0.39$ & $1.12 \pm 0.32$ & $3.679(2,36)$ & 0.034 \\
\hline
\end{tabular}




\begin{tabular}{|c|c|c|c|c|c|}
\hline $\mathrm{C} 4$ & $0.80 \pm 0.33$ & $1.06 \pm 0.80$ & $1.11 \pm 0.59$ & $1.086(2,36)$ & 0.347 \\
\hline T3 & $1.17 \pm 0.67$ & $0.92 \pm 0.63$ & $1.53 \pm 1.09$ & $2.061(2,36)$ & 0.14 \\
\hline $\mathrm{T} 4$ & $0.72 \pm 0.36$ & $1.36 \pm 1.07$ & $0.81 \pm 0.28$ & $3.797(2,36)$ & 0.031 \\
\hline T5 & $1.09 \pm 0.71$ & $0.97 \pm 0.71$ & $1.26 \pm 0.78$ & $0.504(2,36)$ & 0.608 \\
\hline T6 & $0.84 \pm 0.34$ & $1.30 \pm 1.11$ & $0.82 \pm 0.53$ & $1.959(2,36)$ & 0.154 \\
\hline P3 & $0.93 \pm 0.54$ & $0.87 \pm 0.69$ & $1.19 \pm 0.54$ & $1.052(2,36)$ & 0.359 \\
\hline P4 & $0.82 \pm 0.40$ & $1.08 \pm 0.95$ & $0.84 \pm 0.49$ & $0.700(2,36)$ & 0.502 \\
\hline O1 & $1.05 \pm 0.41$ & $1.32 \pm 1.07$ & $1.30 \pm 0.76$ & $0.572(2,36)$ & 0.569 \\
\hline $\mathrm{O} 2$ & $1.00 \pm 0.42$ & $0.94 \pm 0.93$ & $1.40 \pm 0.84$ & $1.416(2,36)$ & 0.254 \\
\hline
\end{tabular}

\section{N100 ERP Component}

Total three electrode channels showed significant difference among groups. $\mathrm{G} 3$ evoked significant difference amplitudes at $\mathrm{Cz}$ between groups $(\mathrm{F}(\mathrm{df})=4.542(2,36), \mathrm{p}=0.017$
G3>G2>G1) (Table 2). The significantly greater amplitudes were observed in the $\mathrm{G} 1$ group at other two sites, $\mathrm{F} 8(\mathrm{~F}(\mathrm{df})=$ $3.503(2,36), p=0.039)$ and $T 4(F(d f)=4.005(2,36), p=0.026$, G1>G3>G2) (Table 2).

Table 2 The amplitudes of N100 ERP component were revealed across groups (control, 2nd trimester pregnancy and 3rd trimester pregnancy).

\begin{tabular}{|c|c|c|c|c|c|}
\hline \multirow{2}{*}{ Sites } & \multirow{2}{*}{$\begin{array}{l}\text { Control (G1) (mean } \pm \\
\text { SD) }\end{array}$} & $\begin{array}{l}\text { 2nd trirmester Pregnancy }\left(G_{2}\right) \\
\text { (mean } \pm \text { SD) }\end{array}$ & $\begin{array}{l}\text { 3rd trimester Pregnancy }(G 3) \\
\text { (mean } \pm \text { SD) }\end{array}$ & $F(d f)$ & \multirow[t]{2}{*}{$\mathbf{p}$} \\
\hline & & \multicolumn{3}{|c|}{ N100 ERP Component Amplitudes (in $\mu \mathrm{V})($ mean \pm SD) } & \\
\hline $\mathrm{Fz}$ & $1.25 \pm 0.88$ & $0.93 \pm 1.03$ & $1.72 \pm 1.26$ & $1.970(2,36)$ & 0.152 \\
\hline $\mathrm{Cz}$ & $0.63 \pm 0.86$ & $1.42 \pm 1.07$ & $1.69 \pm 1.03$ & $4.542(2,36)$ & 0.017 \\
\hline $\mathrm{Pz}$ & $0.67 \pm 1.07$ & $1.63 \pm 1.42$ & $2.30 \pm 2.52$ & $3.269(2,36)$ & 0.048 \\
\hline Fp1 & $1.58 \pm 1.45$ & $1.47 \pm 1.48$ & $2.04 \pm 1.57$ & $0.526(2,36)$ & 0.595 \\
\hline Fp2 & $1.97 \pm 1.41$ & $1.73 \pm 1.36$ & $2.62 \pm 2.42$ & $0.941(2,36)$ & 0.399 \\
\hline F3 & $1.25 \pm 1.18$ & $0.94 \pm 0.81$ & $1.90 \pm 1.21$ & $2.825(2,36)$ & 0.071 \\
\hline $\mathrm{F} 4$ & $1.32 \pm 1.13$ & $0.83 \pm 0.85$ & $1.37 \pm 1.45$ & $1.017(2,36)$ & 0.371 \\
\hline $\mathrm{F} 7$ & $1.04 \pm 1.28$ & $0.90 \pm 0.80$ & $1.23 \pm 0.97$ & $0.335(2,36)$ & 0.717 \\
\hline F8 & $1.28 \pm 0.72$ & $0.53 \pm 0.72$ & $0.73 \pm 1.07$ & $3.503(2,36)$ & 0.039 \\
\hline C3 & $1.09 \pm 0.68$ & $0.82 \pm 0.45$ & $1.46 \pm 0.99$ & $2.796(2,36)$ & 0.073 \\
\hline C4 & $1.30 \pm 0.70$ & $0.87 \pm 0.70$ & $1.22 \pm 1.09$ & $1.219(2,36)$ & 0.306 \\
\hline T3 & $1.19 \pm 0.91$ & $0.93 \pm 1.00$ & $1.39 \pm 0.94$ & $0.817(2,36)$ & 0.449 \\
\hline $\mathrm{T} 4$ & $1.16 \pm 0.47$ & $0.53 \pm 0.79$ & $0.68 \pm 0.67$ & $4.005(2,36)$ & 0.026 \\
\hline T5 & $1.00 \pm 0.93$ & $1.30 \pm 0.98$ & $1.55 \pm 1.13$ & $1.037(2,36)$ & 0.364 \\
\hline T6 & $1.02 \pm 0.55$ & $1.10 \pm 1.00$ & $1.11 \pm 0.95$ & $0.054(2,36)$ & 0.947 \\
\hline P3 & $0.93 \pm 0.62$ & $1.12 \pm 0.73$ & $1.41 \pm 0.99$ & $1.350(2,36)$ & 0.271 \\
\hline P4 & $1.25 \pm 0.45$ & $0.84 \pm 0.56$ & $1.22 \pm 1.02$ & $1.728(2,36)$ & 0.19 \\
\hline 01 & $0.96 \pm 0.64$ & $1.80 \pm 1.25$ & $1.42 \pm 1.90$ & $3.030(2,36)$ & 0.059 \\
\hline $\mathrm{O} 2$ & $0.72 \pm 0.83$ & $1.62 \pm 1.79$ & $1.52 \pm 1.37$ & $1.936(2,36)$ & 0.157 \\
\hline
\end{tabular}




\section{P300 Component}

Between-group comparisons of the P300 ERP component are shown in Table 3. Significant differences in amplitudes were identified at Fz $(G 3>G 2>G 1)$ and FP1 $(G 2>G 3>G 1)(p=$
0.028 and $p=0.015$, respectively). The group effects were $F$ $(d f)=3.925(2,36)$ and $F(d f)=4.625(2,36)$, respectively (Table 3). Within pregnant group, G2 evoked higher amplitudes of P300 component at FP1 $(8.28 \pm 4.52 \mu \mathrm{V})$ comparing with the $\mathrm{G} 3$ group at Fz location $(5.87 \pm 2.73 \mu \mathrm{V}$ ) (Table $\mathbf{3}$ ).

Table 3 The amplitudes of P300 ERP component were shown among groups (control, 2nd trimester pregnancy and 3rd trimester pregnancy).

\begin{tabular}{|c|c|c|c|c|c|}
\hline \multirow{2}{*}{ Sites } & \multirow{2}{*}{$\begin{array}{l}\text { Control (G1) (mean } \pm \\
\text { SD) }\end{array}$} & $\begin{array}{l}\text { 2nd trirmester Pregnancy(G2) (mean } \\
\pm \text { SD) }\end{array}$ & $\begin{array}{l}\text { 3rd trimester Pregnancy(G3) } \\
(\text { mean } \pm \text { SD) }\end{array}$ & $F(d f)$ & \multirow[t]{2}{*}{$\mathbf{p}$} \\
\hline & & \multicolumn{3}{|c|}{ P300 ERP Component Amplitudes (in $\mu \mathrm{V})($ mean \pm SD) } & \\
\hline Fz & $3.03 \pm 2.45$ & $5.09 \pm 3.21$ & $5.87 \pm 2.73$ & $3.925(2,36)$ & 0.028 \\
\hline $\mathrm{Cz}$ & $0.63 \pm 2.40$ & $2.02 \pm 2.37$ & $1.27 \pm 2.23$ & $1.417(2,36)$ & 0.254 \\
\hline $\mathrm{Pz}$ & $1.19 \pm 2.25$ & $1.30 \pm 3.53$ & $1.56 \pm 3.18$ & $0.052(2,36)$ & 0.949 \\
\hline $\mathrm{Fp} 1$ & $4.25 \pm 3.92$ & $8.28 \pm 4.52$ & $7.85 \pm 3.48$ & $4.625(2,36)$ & 0.015 \\
\hline $\mathrm{Fp} 2$ & $6.16 \pm 3.45$ & $7.20 \pm 5.10$ & $6.73 \pm 4.94$ & $0.215(2,36)$ & 0.808 \\
\hline F3 & $2.50 \pm 3.67$ & $4.02 \pm 2.65$ & $5.00 \pm 2.60$ & $2.415(2,36)$ & 0.102 \\
\hline F4 & $3.46 \pm 2.43$ & $3.24 \pm 2.57$ & $5.87 \pm 5.20$ & $2.359(2,36)$ & 0.107 \\
\hline F7 & $2.23 \pm 2.92$ & $2.93 \pm 1.97$ & $3.60 \pm 3.36$ & $0.847(2,36)$ & 0.436 \\
\hline F8 & $3.04 \pm 2.43$ & $3.15 \pm 3.20$ & $2.81 \pm 1.14$ & $0.067(2,36)$ & 0.936 \\
\hline C3 & $1.26 \pm 1.19$ & $1.47 \pm 1.84$ & $1.25 \pm 1.25$ & $0.110(2,36)$ & 0.896 \\
\hline C4 & $1.58 \pm 1.13$ & $1.88 \pm 1.40$ & $1.48 \pm 1.80$ & $0.305(2,36)$ & 0.739 \\
\hline T3 & $2.43 \pm 2.11$ & $1.80 \pm 2.39$ & $2.28 \pm 3.25$ & $0.261(2,36)$ & 0.772 \\
\hline $\mathrm{T} 4$ & $2.79 \pm 2.05$ & $2.20 \pm 2.02$ & $2.76 \pm 2.59$ & $0.344(2,36)$ & 0.711 \\
\hline T5 & $1.99 \pm 1.64$ & $0.89 \pm 2.04$ & $1.17 \pm 1.68$ & $1.571(2,36)$ & 0.22 \\
\hline T6 & $1.85 \pm 1.27$ & $1.38 \pm 1.53$ & $1.51 \pm 2.06$ & $0.359(2,36)$ & 0.7 \\
\hline P3 & $1.11 \pm 1.19$ & $0.37 \pm 1.69$ & $1.03 \pm 2.37$ & $0.844(2,36)$ & 0.437 \\
\hline P4 & $1.50 \pm 1.65$ & $0.93 \pm 1.28$ & $0.69 \pm 2.17$ & $0.852(2,36)$ & 0.434 \\
\hline 01 & $2.26 \pm 2.96$ & $1.07 \pm 3.57$ & $1.73 \pm 2.21$ & $0.618(2,36)$ & 0.544 \\
\hline $\mathrm{O} 2$ & $1.82 \pm 1.42$ & $1.35 \pm 2.52$ & $1.26 \pm 1.47$ & $0.373(2,36)$ & 0.691 \\
\hline
\end{tabular}

\section{Neuropsychological Tests}

The neuropsychological test scores are shown for the three groups in Table 4. Six neuropsychological tests were conducted. The highest (significantly) scores were found in WCST, ZCT and nearly significant difference was in RAVLTim within group.

For the WCST, the highest scores (lowest marks in case of WCST) were found in the G2 group, compared with the $\mathrm{G} 1$ and $\mathrm{G} 3$ groups (G2>G1>G3). In case of the $Z C T$, and the results revealed that the $\mathrm{G} 1$ group had the highest (significantly) score, followed by the G3 and G2 groups (G1>G3>G2).
The highest scores on the RAVLT were achieved in the $\mathrm{G} 2$ group, followed by the G3 and G1 groups. In the RAVLTim, G2 subjects exhibited the nearly significant $(p=0.099)$ (the highest score among three groups), while G1 subjects exhibited the lowest scores (G2>G3>G1). The WCST (F (df) = $843.776(2,36), p=0.001)$ and ZCT $(F(d f)=528.598(2,36), p=$ $0.001)$ revealed significant differences between groups.

In contrast, no significant between-group differences were found in PAS ( $p=0.693)$, RAVLTs $(p=0.375)$ or RAVLTdr $(p=$ 0.505) (Table 4).

Table 4 The scores of different neuropsychology tests among G1, G2 and G3. 


\begin{tabular}{|c|c|c|c|c|c|}
\hline Neuro-psychology test & $\begin{array}{l}\text { Control (G1) (mean } \pm \\
\text { SD) }\end{array}$ & $\begin{array}{lr}\text { 2nd } & \text { trirmester } \\
\text { Pregnancy } & (G 2) \text { (mean } \pm \\
\text { SD) }\end{array}$ & $\begin{array}{l}\text { 3rd } \quad \text { trimester } \\
\text { Pregnancy(G3) } \text { (mean } \\
\pm \text { SD) }\end{array}$ & $F(d f)$ & p \\
\hline PAS & $41.50 \pm 9.95$ & $45.58 \pm 17.41$ & $45.00 \pm 11.64$ & $0.370(2,36)$ & 0.693 \\
\hline WCST & $2.14 \pm 1.41$ & $1.58 \pm 1.83$ & $2.42 \pm 1.73$ & $843.776(2,36)$ & 0.001 \\
\hline ZCT & $27.50 \pm 1.95$ & $26.75 \pm 2.90$ & $26.42 \pm 2.27$ & $528.598(2,36)$ & 0.001 \\
\hline RAVLTs & $50.93 \pm 6.31$ & $58.00 \pm 19.99$ & $56.33 \pm 11.06$ & $1.009(2,36)$ & 0.375 \\
\hline RAVLTim & $5.29 \pm 2.61$ & $7.83 \pm 3.97$ & $7.08 \pm 2.27$ & $2.471(2,36)$ & 0.099 \\
\hline RAVLTdr & $17.00 \pm 6.86$ & $13.00 \pm 6.45$ & $16.67 \pm 13.46$ & $0.698(2,36)$ & 0.505 \\
\hline
\end{tabular}

\section{Discussion}

The current study assessed auditory cognitive function assessment using the ERP components of the P50, N100 and P300 evoked by auditory oddball stimuli, reflecting auditory sensory gating, perception and attention, respectively. Meanwhile, executive function and auditory attention and memory of subjects were assessed through four neuropsychological tests: the PAS, WCST, ZCT and RAVLT (RAVLTts, RAVLTim and RAVLTdr).

The current finding that the G3 group exhibited the greatest (significantly) P50 and N100 amplitudes is in accord with a previous study regarding the progesterone levels at different stages of pregnancy, reporting higher levels in the third trimester compared with pregnant women in the second trimester and a non-pregnant group [18]. The P50 and N100 ERP components indicated the sensory gating and sensory perception, respectively and their relationship with higher order cognitive function (attention) is negative [19]. The early P50 and N100 components reflect the neural origin of somatosensory processing, which is also known as sensory gating of cognitive function, as indicated by Desment and Tomberg's finding that the somatosensory processes underlying early ERP components are sensitive to cognitive factors determining the direction of attention [20]. Studies suggested that higher amplitudes of P50 ERP component indicated sensory overload which is the failure of filtering mechanism [21-23] and it leads inadequate attention [22,23]. Low amplitudes and short latencies in both the P50 and N100 components are thought to indicate good cognitive performance [24]. A review by Luck reported that the P50 component in response to auditory clicks reflects the flow of auditory information from the thalamus to the auditory cortex. Thus, this component is thought to be related to sensory gating detection, or pre-attentive processing directed towards a stimulus [25]. A study by Begum et al. of auditory cognitive functional assessment during the second trimester of pregnancy focused on the N100 and P300 ERP components using an auditory oddball paradigm. Based on Begum et al. findings, we examined whether a third trimester pregnant group exhibited reduced auditory perception compared with a second trimester pregnant group [10]. In the current study, the G3 group exhibited the greatest (significantly) P50 (at three sites out of three) and N100 amplitudes (at one sites out of three), and the highest (significantly) P300 amplitudes at one site out of two sites (Tables 1-3). Moreover, the G2 group exhibited the smallest (significantly) amplitudes of the N100 component at two sites (F8, T4), indicating that G2 subjects may have exhibited better auditory perception compared with G3 subjects. Kumar and Magon suggested that higher progesterone levels during third trimester pregnancy can reduce cognitive function (attention) [26] but the level of attention still greater than control participants. Taking all the suggestions, we assume that G3 subjects have sensory overload (as significant highest amplitude in P50 at 3 sites), less sensory perception (as significant highest amplitude in $\mathrm{N} 100$ at one site) comparing with the $\mathrm{G} 1$ and $\mathrm{G} 2$ which might be the effect of high progesterone during 3rd trimester of pregnancy.

It was documented that higher amplitude of the P300 amplitude can be evoked during higher attention [27]. The P300 amplitude was increased $[9,10]$ and decreased $[7,8]$ in different studies in pregnant group. However, the experimental paradigm was different in each study. The current P300 results suggest higher auditory cognitive function/attention (significant higher amplitudes of P300 at two sites) among pregnant groups (G2 and G3) comparing with the $\mathrm{G} 1$ group. P300 amplitude was the greatest (significantly) in the $\mathrm{G} 2$ group (at FP1) and second greatest at Fz, suggesting a high level of auditory cognitive function/attentional function in the second trimester of pregnancy. Comparing the two sites of P300 amplitudes at FP1 and Fz, G2 subjects evoked higher P300 amplitude (at FP1, $8.28 \pm 4.52 \mu \mathrm{V}$ ) comparing with the G3 subjects (at Fz, $5.87 \pm 2.73 \mu \mathrm{V}$ ) (Table 3 ). These P300 findings may suggest that later stages of pregnancy involve reduced attention comparing with the 2 nd trimester pregnant group but still better attention than control group (higher P300 amplitude comparing with G1) (Table 3).

The $\mathrm{G} 2$ group exhibited better executive function in terms of auditory attention and memory, compared with the G3 group. However, the ERP results need to be integrated with neuropsychological testing to provide comprehensive understanding of executive functions in auditory memory and attention. The current neuropsychological test data (Table 4) revealed that the $\mathrm{G} 2$ group exhibited the highest scores on the WCST (significantly) and RAVTIM (nearly significantly), while 
the second-highest scores were achieved by the G3 group on the ZCT and RAVTIM. The G1 subjects revealed the highest (significantly) score in ZCT and 2nd highest score in WCST (Table 4). Overall, pregnant group (G2, G3) revealed better performance compared with the $\mathrm{G} 1$ group as pregnant group gained the highest scores at two tests (significantly) and control group gained the highest in one test (significantly). On the other hand, the high performance of the $G 2$ group may suggest better executive function, auditory memory and attention than the $\mathrm{G} 3$ group.

The good performance of WCST test was based on the low error rate, while the good performance in the RAVLT and ZCT tests depends on the higher score $[28,29]$. There is lack of neuropsychology studies on pregnant women using various types of tests. However, one study used concept shifting test (CST), Stroop test, letter digit substitution test (LDST), visual verbal word learning test (WLT) to assess speed processing, memory and attention among pregnant women. This study found that the performance of pregnant women was poorer compared with the control group [30]. However, these tests are different from our current study and we found that pregnant group performed better compared with the control which is the opposite interpretation from Groot et al. study. As our 2nd trimester group revealed the highest score in two tests compared with the 3rd trimester group, therefore we conclude that 2 nd trimester subjects performed better than 3rd trimester subjects.

\section{Conclusion}

The current results indicated improved auditory cognitive function among pregnant subjects compared with nonpregnant groups. In addition, neuropsychological test results indicated better executive function, auditory memory and attention during mid trimester than third trimester pregnancy. To our knowledge, no previous study has used combined ERP and neuropsychological tests to compare cognitive function between different trimesters of pregnancy using auditory oddball stimulation. The current findings have a range of potential applications and may aid pregnant women to develop better therapeutic strategies to improve their quality of life.

\section{Conflicts of Interest and Funds}

All authors declared that they have no conflicts of Interest. This study was supported by the short-term grant of Universiti Sains Malaysia (USM) (304/PPSP/61313160).

\section{Acknowledgments}

We thank Benjamin Knight, MSc, from Edanz Group (www.edanzediting.com/ac) for editing a draft of this manuscript.

\section{References}

1. Janes C, Casey P, Huntsdale C, Angus G (1999) Memory in pregnancy. I: Subjective experiences and objective assessment of implicit, explicit and working memory in primigravid and primiparous women. J Psychosom Obstet Gynaecol 20: 80-87.

2. Brett M, Bexandale S (2001) Motherhood and Memory: A review. Psychoneuroendocrinology 26: 339-362.

3. Poser CM, Kassirer MR, Peyser JM (1986) Benign encephalopathy of pregnancy: Preliminary clinical observation. Acta Neurologica Scandanavia 73: 39-43.

4. Buckwalter JG, Stanczyk FZ, McCleary CA, Bluestein BW, Buckwalter DK, et al. (1999) Pregnancy the postpartum and steroid hormones: Effects on cognition and mood. Psychoneuroendocrinology 24: 69-84.

5. Grut M, Jorm AF, Fratiglioni L, Forsell Y, Viitanen M, et al. (1993) Memory complaints of elderly people in a population surveyvariation according to dementia stage and depression. J Am Geriatr Soc 41: 1295-1300.

6. Key APF, Dove GO, Maguire MJ (2005) Linking brainwaves to the brain: An ERP primer. Dev Neuropsychol 27: 183-215.

7. Landa L, Krpoun Z, Kolarova M, Kasparek T (2014) Event related potentials and their applications. Activitas Nervosa Superior 56: $1-2$.

8. Raj S (2014) Behavioural and neural correlates of cognitive affective function during late pregnancy: An event related potential. Behaviour Brain Res 267: 17-25.

9. Tandon OP, Bhatia R, Goel N (1996) P3 event related evoked potentials in pregnancy. Indian J of Physiol Pharmacol 40: 345-349.

10. Begum T, Reza F, Wan R, Wan NA (2016) Mild auditory cognitive impairment in midtrimester pregnancy. Merit Research Journal of Medicine and Medical Sciences 4: 260-265.

11. Walia R, Aggarwal A, Wadhwa Y (2013) Investigating EEG characteristics of a pregnant woman. International Journal of Emerging Research in Management and Technology 2: 14-21.

12. Begum T, Reza F, Ahmed I, Abdullah JM (2014) Influence of education level on design induced N170 and P300 components of event related potentials in the human brain. J Integr Neurosci 13: 71-88.

13. Hasan RA, Reza F, Begum T (2016) Education level is associated with specific N200 and P300 profiles reflecting higher cognitive functioning. Journal of Advances in Medical and Pharmaceutical 10: $1-12$.

14. Saedi E, Gheini MR, Faiz F, Arami MA (2016) Diabetes mellitus and cognitive impairments. World J Diabetes 7: 412-422.

15. Etgen T (2015) Kidney Disease as a Determinant of Cognitive Decline and Dementia. Alzheimers Res Ther 7: 29.

16. Houston RJ, Derrick J, Leonard K, Testa M, Quigley B, et al. (2014) Effects of heavy drinking on executive cognitive functioning in a community sample. Addictive Behaviors 39: 345-349.

17. Feng L, Ng XT, Yap P, Li J, Lee TS, et al. (2014) Marital status and cognitive impairment among community-dwelling Chinese older adults: The role of gender and social engagement. Dement Geriatr Cogn Dis Extra 4: 375-384. 
18. Schock H, Zeleniuch-Jacquotte A, Lundin E, Grankvist K, Lakso $\mathrm{HA}$, et al. (2016) Hormone concentrations throughout uncomplicated pregnancies: A longitudinal study. BMC Pregnancy Childbirth 16: 146.

19. Yadon CA, Bugg JM, Kisley MA, Davalos DB (2009) P50 sensory gating is related to performance on select tasks of cognitive inhibition. Cogn Affect Behav Neurosci 9: 448-458.

20. Desmedt JE, Tomberg C (1989) Mapping early somatosensory evoked potentials in selective attention: critical evaluation of control conditions used for titrating by difference the cognitive P30, P40, P100 and N140. Electroencephalogr Clin Neurophysiol 74: 321-346.

21. Venables PH (1964) Input dysfunction in schizophrenia. Prog Exp Pers Res 72: 1-47.

22. Desimone R, Duncan J (1995) Neural mechanisms of selective visual attention. Annu Rev Neurosci 18: 193-222.

23. Làdavas $E$, Petronio $A$, Umiltà $C(1990)$ The deployment of visual attention in the intact field of hemineglect patients. Cortex 26: 307-317.

24. Golob EJ, Irimajiri R, Starr A (2007) Auditory cortical activity in amnestic mild cognitive impairment: Relationship to subtype and conversion to dementia. Brain 130: 740-752.
25. Luck SJ (2012) Event-related potentials. Handbook of Research Methods in Psychology. Foundations, Planning, Measures, and Psychometrics. Washington, DC: American Psychological Association, USA.

26. Kumar P, Magon N (2012) Hormones in pregnancy. Niger Med J 53: 179-183.

27. Medvidovic S, Titlic M, Maras-Simunic M (2013) P300 evoked potential in patients with mild cognitive impairment. Acta Inform Med 21: 89-92.

28. Mgalhaes SS, Hamdan AC (2010) The rey auditory verbal learning test: Normative data for the Brazilian population and analysis of the influence of demographic variables. Psychology and Neuroscience 3: 85-91.

29. Fabriguole C, Rouch I, Taberly A, Letenneur L, Commenges D, et al. (1998) Cognitive process in preclinical phase of dementia. PubMed 121: 135-141.

30. Groot RHMD, Vuurman EFPM, Hornstra G, Jolles J (2006) Differences in cognitive performance during pregnancy and early motherhood. Psychological Medicine 36: 1023-1032. 